\title{
LAS DIGRESIONES DEL LENGUAJE, MEA CULPA, FASTIDIUM, DUBITATIO, Y CARNAVAL EN LA FLORIDA DEL INCA GARCILASO DE LA VEGA
}

\author{
Charles B. Moore
}

\begin{abstract}
RESUMEN
Aunque mucho se ha escrito sobre los Comentario reales del Inca Garcilaso de la Vega, su crónica sobre la exploración de Hernando de Soto en el sureste de Norteamérica (1539-43) nunca ha gozado de la misma recepción. Sea por su supuesta descripción novelizada de dicha aventura o los lugares lejanos de los centros del poder colonial que recuenta, La Florida nunca ha formado parte del canon colonial. Por eso, este trabajo intenta explorar cinco tipos de digresiones clásicas que el Inca pudo haber empleado para embellecer la obra, impresionar a sus críticos y así realzar su renombre como uno de los historiadores más grandes sobre el Nuevo Mundo.

Palabras clave: el Inca Garcilaso, La Florida, digresiones, tópicos clásicos, siglo XVII.
\end{abstract}

\begin{abstract}
Although much has been written about el Inca Garcilaso de la Vega's Comentario reales, his chronicle about Hernando de Soto's adventure in the American southeast has never enjoyed the same reception. Be it for its supposed novelization of the adventure or for the far-away lands which it describes, the work has never been part of the colonial cannon. For that reason, this essay intends to study five classical digressions which el Inca may have used to embellish the work, impress his critics, and therefore, enhance his reputation as one of the greatest New World historians of his time. Key words: el Inca Garcilaso, La Florida, classical topics, digressions, XVII century.
\end{abstract}

\section{Introducción}

Después de los desastres de Juan Ponce de León en la Florida $(1513,1521)$, Lucas Vázquez de Ayllón en Georgia y Carolina del Sur (1526) y Pedro de Narváez con Cabeza de Vaca en la Florida y el Golfo de México (1528), parecía que la exploración española en el sureste de América del Norte (conocida en aquel entonces como La Florida) se destinaba al fracaso.

\footnotetext{
Charles B. Moore. Profesor de español. Gardner- Webb University, Carolina del Norte.

Correo electrónico: cmoore@gardner-webb.edu
} 
Pero entre 1539-43, tal vez el conquistador más famoso de todos, Hernando de Soto, creía que él podía cambiar la suerte de España en la región y así ganar la fama y el reconocimiento que tanto anhelaba durante y después de sus muchos años de conquista en Darién y Perú.

A diferencia de Cortés y Cabeza de Vaca, por ejemplo, Soto murió antes de que pudiera escribir sobre sus experiencias. Asimismo, la memoria colectiva que quedaba de su desastrosa aventura murió poco después cuando los soldados que habían sobrevivido los constantes ataques indios, el hambre y la enfermedad, escaparon a México por el Río Mississippi. Unos sesenta años después, sin embargo, el Inca Garcilaso de la Vega, amigo de uno de los soldados que acompañó a Soto a la Florida, publicó La Florida del Inca (1605) para salvar del olvido las hazañas del gran conquistador español en el sureste de Norteamérica. Esta historia, tanto loada como criticada por novelizar la expedición de Soto, curiosamente se ha quedado marginada del canon historiográfico de la época colonial. Sin embargo, sigue siendo una de las mejores fuentes de información que existe sobre las civilizaciones indígenas y paisajes que conoció esta cuarta y quizás más controversial de todas las expediciones españolas en el sureste de la América del Norte.

Este estudio pretende explorar cómo el Inca logra embellecer La Florida a través de una variedad de digresiones. Además de romper lo que podría ser una historia monótona de guerra y conquista, tales digresiones permiten que el Inca demuestre su propia erudición clásica, divulgue algo sobre su vida personal y se acerque en forma más íntima a un público ya escéptico de un autor mestizo de una tierra lejana y extraña como le era el Perú.

\section{La digresión del lenguaje}

Unas de las digresiones más larga en La Florida es donde el Inca recuerda su conocimiento del lenguaje quechua. Estrechamente ligadas a otras que estudiaremos, donde el autor se pone a la defensa por su herencia indígena. Ambas, comparadas con el carácter estático de sus múltiples sentencias, especialmente revelan la nostalgia y emoción que los críticos han observado en las obras del Inca (i.e. Lavalle 1982: 141). En el capítulo titulado "Lo que sucedió a Juan Ortiz con los españoles que por él iban”, el Inca reflexiona:

[. . . con el poco o ningún uso que entre los indios había tenido [Juan Ortiz] de la lengua castellana, se
le había olvidado hasta el pronunciar el nombre de la propria tierra, como yo podré decir también de mí
mismo que por no haber tenido en España con quien hablar mi lengua natural y materna, que es la general
que se habla en todo el Perú [ . . .] (1965: 281; lib. II, pt. I, cap. VI).

Parece exponer su soledad cuando confiesa que no tiene con quien hablar su lengua natal. Esta soledad, a su vez, lo lleva a recordar más del pasado, como vemos a continuación:

[ . . .] aunque los incas tenían otro [lenguaje] particular que hablaban entre sí unos con otros, se me ha olvidado [su lengua] de tal manera que, con saberla hablar tan bien y mejor y con más elegancia que los mismos indios que no son incas, porque soy hijo de palla y sobrino de incas, que son los que mejor y más apuradamente la hablan por haber sido lenguaje de la corte de sus principes y haber sido ellos los principales cortesanos, no acierto ahora a concertar seis o siete palabras en oración para dar a entender lo que quiero decir [. . .] (1965: 281).

Como vemos frecuentemente, el Inca irónicamente enfatiza lo que tiene a través de lo que no tiene. Aquí promueve su linaje real a la vez que lamenta su falta de vocabulario. Pero aunque le falta la lengua, aún tiene la sangre necesaria para afirmar su alta posición social.

Pero el Inca todavía no se ha desahogado suficientemente porque sigue: 
[. . .] y más, que muchos vocablos se me han ido de la memoria, que no sé cuáles son, para nombrar en indio tal o tal cosa. Aunque es verdad que, sí oyese hablar a un inca, lo entendería todo lo que dijese y, si oyese los vocablos olvidados, diría lo que significan; empero, de mí mismo, por mucho que lo procuro, no acierto a decir cuáles son. Esto he sacado por experiencia del uso o descuido de las lenguas, que las ajenas se aprenden con usarlas y las proprias se olvidan no usándolas (1965:281-82).

Explica que aunque puede entender si oye el lenguaje, no puede "producirlo" por su cuenta. La "experiencia" es la maestra que le ha enseñado esta valiosa lección y ahora parece pasarla a sus lectores para que no cometan el mismo error. Aquí el Inca emplea el contentio (Cicerón, De Oratore II, 1976:162), o el contraste de opuestos (“uso"- "descuido", "ajenas" "proprias," "usarlas"- "no usándolas") para iluminar irónicamente la idea por contrastarla con lo que no es. La experiencia y los recuerdos informan de la nostalgia surgida más que nunca cuando el Inca habla de lo que lo conecta más que nada con el pasado: su lenguaje natal.

La digresión aquí también se usa efectivamente para manipular al lector. El Inca espera hasta el final para "recordar" que dejó a Juan Ortiz en suspense mientras disertaba largamente sobre sus lamentos y felicidades personales. Cuando dice, "[v]olviendo a Juan Ortiz, que lo dejamos en gran peligro de ser muerto por los que más deseaban verlo vivo [. . .]" (1965: 282), reconoce que su lector podría estar impaciente por volver a la historia. Igual que en otros momentos de La Florida (i.e. 262, 271, 285, 333-36), se cree que esta técnica de dejar al lector en suspense en el momento culminante de la historia se deriva de la novela bizantina (i.e. véase a Dowling 1997: 114-15).

Como vimos arriba, el Inca admite que ya no puede hablar bien su idioma incaico natal. En el Capítulo XI, de "Cómo se empieza el descubrimiento y la entrada de los españoles la tierra adentro", vuelve al mismo tema de su lenguaje en pleno discurso de la llegada de los españoles a un pueblo indio abandonado. Cuando el jefe indio saluda a los españoles, Garcilaso inserta:

\footnotetext{
[...] nunca el curaca quiso salir de paz, ni hizo guerra a los castellanoss (sic), ni les dio mala respuesta.

Excusóse con palabras comedidas y razones que, aunque frívolas y vanas, le valieron.

Este nombre curaca, en lengua general de los indios del Perú, significa lo mismo que cacique en lenguaje de la isla Española y sus circunvecinas, que es señor de vasallos. Y pues yo soy indio del Perú y no de $\mathrm{S}$. Domingo ni sus comarcanas se me permita que yo introduzca algunos vocablos de mi lenguaje en esa mi obra, porque se vea que soy natural de aquella tierra y no de otra (1965: 288).
}

Él se distingue, como peruano, por pedir permiso para usar "curaca" por el mejor conocido “cacique." Aunque dijo que no sabía muchas palabras incaicas, esta digresión se usa para probar que no todas se le han olvidado totalmente.

Hay todavía otra clase de digresión del lenguaje que muestra los conocimientos etimológicos del Inca. Este interés en la historia de los nombres, letras, sílabas y significados de palabras proviene del pensamiento escolástico y se ve en otros géneros literarios del Siglo de Oro (Paravicino 1994: 230n44); se cree que, también, tiene origen árabe (Cruz-Hernández 1977: 65) o posiblemente sea un fenómeno judío desarrollado en la Cábala española (Smith 1978: 44-45). Sea cual fuera su origen, este tipo de comentario podría ejemplificar el "bagaje" de inferioridad que el Inca llevaba consigo, como vemos en el Capítulo XIII del Libro Segundo, nombrado: "Pasan mal dos veces la ciénega grande y el gobernador sale a buscarle paso y lo halla." Aquí, antes de hablar de exactamente qué "males" ocurren en la ciénega, el Inca explica de donde proviene el mismo nombre de este tipo de lugar: "[. . .] fuesen a descubrir paso a la ciénega que estaba tres leguas del pueblo. La cual era grande y muy dificultosa de pasar por ser de una legua en ancho y tener mucho cieno, de donde toman el nombre de ciénega, y muy hondo a las orillas" (1965: 291). Demuestra que el lodo, o "cieno", que se deposita en las aguas 
estancadas, es la raíz del lugar y palabra, "ciénega". Además de ofrecer a sus lectores una explicación "biológica" de un lugar poco conocido, Garcilaso les puede impresionar con una “interpretación,” o conexión entre palabras, recomendada en la retórica1.

En el mismo capítulo, otra digresión define detalladamente las diferentes razas de los americanos. Rabasa ofrece una posible explicación de por qué el Inca hubiera estado tan interesado en este tipo de discurso:

[. . . ] Garcilaso always positioned himself as a nonauthor; namely, as the translator of León Hebreo's Diálogos de Amor, as the amanuensis of la Florida del Inca, and as the glosser and commentator of the Comentarios reales de los Incas. These writing practices situated Garcilaso either at the borders or on the margins of discourse. Undoubtedly, writing from the borders and margins paralleled his illegitimacy as a bastard, a mestizo, and an Indian (2000: 199-200).

Con este acercamiento a su oficio en mente, puede que el Inca escribiera esta larga digresión:

El gobernador Hernando de Soto, con mucho contento de haberlo hallado, mandó a dos soldados naturales de la isla de Cuba, mestizos, que así nos llaman en todas las Indias Ocidentales a los que somos hijos de español y de india o de indio y española, y llaman mulatos, como en España, a los hijos de negro y de india o de indio y de negra. Los negros llaman criollos a los hijos de español y española y a los hijos de negro y negra que nacen en Indias, por dar a entender que son nacidos allá y no de los que van de acá de España. Y este vocablo criollo han introducido los españoles ya en su lenguaje para significar lo mismo que los negros. Llaman asimismo cuarterón o cuatratuo al que tienen cuarta parte de indio, como es el hijo de español y de mestiza o de mestizo y de española. Llaman negro llanamente al guineo, y español al que lo es. Todos estos nombres hay en Indias para nombrar las naciones intrusas no naturales de ella (1965: 292).

Usa el objeto directo "nos" y el verbo "somos" para asegurarse de que sabemos que él sí pertenece a un grupo oficial en la lista. Según él, no importa el rótulo que uno tenga (español, criollo, mestizo, negro, cuarterón, o mulato) porque todos son "intrusos" en América. Solamente los indios son los verdaderos americanos.

\section{La digresión como mea culpa}

De vez en cuando, Garcilaso emplea largas digresiones para disculparse a sí mismo o defender a otros ante el lector. Para dramatizar y enfatizar la disculpa, que a veces tiene un tema político, usa herramientas frecuentemente recomendadas por los retóricos antiguos. Estos comentarios son transiciones conversacionales entre capítulos, también le permiten salir del tema para dirigirse a cualquier inquietud que el lector tenga sobre su obra.

Al final del Capítulo XII, sobre "La relación que Baltasar de Gallegos envió de lo que había descubierto", el Inca se interrumpe para decir:

En este rumbo [al norte], y en todos los demás que en esta historia se dijeren, es de advertir que no se tomen precisamente para culparme si otra cosa pareciere después cuando aquella tierra se ganare, siendo Dios servido, que, aunque hice todas las diligencias necesarias para poderlos escribir con certidumbre, no me fue posible alcanzarla porque, como el primer intento que estos castellanos llevaban era conquistar aquella tierra y buscar oro y plata, no atendían a otra cosa que no fuese planta y oro, por lo cual dejaron de hacer otras cosas que les importaban más que el demarcar la tierra. Y esto basta para mi descargo de no haber escrito con la certinidad que he deseado y era necesario (1965: 291; lib. II, pt. I) ${ }^{2}$.

Su disculpa a la vez crítica a los españoles ("como el primer intento estos castellanos llevaban era conquistar aquella tierra y buscar oro"). Según él, su trabajo tiene errores porque para los españoles no era una prioridad medir distancias y anotar lugares, por preocuparse más de 
conquistar y enriquecerse primero. Sin embargo, aunque sus fuentes no podían precisarle los lugares y las distancias, con ethos explica que él ha hecho todo lo posible por corregir este descuido.

Luego, el sujeto de la disculpa cambia de sí mismo a los soldados. Aquí, cuando los españoles perdieron una oportunidad para cristianizar a los indios, el Inca habla de ellos en forma más conciliatoria:

\begin{abstract}
[. . .] y así fue gran lástima que no le [al cacique Mucozo] convidasen con el agua del bautismo, que, según su buen juicio, pocas persuasiones fueran menester para sacarlo de su gentilidad y reducirlo a nuestra Fe Católica. Y fuera un galano principio para esperar que tal grano echara muchas espigas y hubiera mucha mies. Mas no es de culparles, porque estos cristianos habían determinado de predicar y administrar los sacramentos de nuestra ley de gracias después de haber conquistado y hecho asiento en la tierra, y esto les entretuvo para que no los administraran desde luego. Y esto quede aquí dicho para que sirva de disculpa y descargo de estos castellanos de haber tenido el mismo descuido en otros semejantes pasos [. . .] (1965: 343; lib. II, pt. II, cap. XVI).
\end{abstract}

Irónicamente, ahora el Inca parece estar más dispuesto a excusar a los españoles por no bautizar al cacique en este momento que por no haber anotado direcciones con exactitud. La excusa es que siguen un "plan" sistematizado: conquistar y asentarse antes de evangelizar.

En su próxima digresión de disculpa, el Inca emplea el antiguo tópico de la modestia afectada para insistir en su propia debilidad e incapacidad de tratar dignamente el asunto. Es probable que aquí siga a Cicerón, quien recomendó que el orador se presentara con una actitud humilde y suplicante así para captar la benevolencia del público (Curtius 1955: 128). Al terminar el Capítulo XIV del Libro Tercero dice:

\footnotetext{
En medio del pueblo, frontero de las casas del señor, estaba el templo o casa de entierro que los españoles iban a ver, la cual tenía cosas admirables en grandeza, riqueza, curiosidad y majestad, extrañamente hechas y compuestas, que estimara yo en mucho saberlas decir como mi autor deseaba que se dijeran. Recíbase mi voluntad y lo que yo no acertare a decir quede para la consideración de los discretos que suplan con ella lo que la pluma no acierta a escribir, que cierto, particularmente en este paso y en otros tan grandes que en la historia se hallarán, nuestra pintura queda muy lejos de la grandeza de ellos y de lo que se requería para los poner como ellos fueron. De donde diez y diez veces, frasis del lenguaje del Perú por muchas veces, suplicaré encarecidamente se crea de veras que antes quedo corto y menoscabado de lo que convenía decirse que largo y sobrado en lo que se hubiere dicho (1965: 381).
}

Aunque la descripción de estas construcciones no pueden igualar su belleza, pide con modestia afectada que el lector acepte de todos modos lo que humildemente le ofrece. A través del tópico del fastidium (Cicerón, De Oratore II, 1976: 164) expresa además su deseo de hablar brevemente.

Como hemos visto, a veces el Inca reconoce que ha divagado de una de sus propias digresiones. Para sentar las bases para una digresión así, medita brevemente en el Capítulo IX del Libro Sexto de lo que podía ser. Primero explica que para conquistar al Nuevo Mundo los españoles tienen beneficios de la navegación fácil desde España, mucho espacio para criar caballos en México, y el socorro en Cuba, Santo Domingo, Nueva España y Tierra Firme también. Entonces el Inca se posiciona a sí mismo en forma humilde y suplicante para contrastar con tales ventajas:

De mí sé decir que si, conforme el ánimo y deseo, hubiera dado el Señor la posibilidad, holgara gastarla juntamente con la vida con esta heroica empresa. Mas ella se debe de guardar para algún bien afortunado, que tal será el que la hiciere, y entonces se verificarán las faltas de mi historia, de que he pedido perdón muchas veces. Y con esto volvamos a ella, que, por el afecto y deseo de verla acabada, ni huyo al trabajo que me es incomportable, ni perdono a la flaca salud, que anda ya muy gastada, ni la deseo ya para otra cosa, porque España, a quien debo tanto, no quede sin esta relación, si yo faltase antes de sacarla a luz (1965: 502). 
Concluye con modestia afectada que es mejor que un participante en la conquista corrija sus errores. Entonces el "volvamos" señala la transición de la digresión a la misma historia de que pide perdón ${ }^{3}$. Con pathos explica que su servicio ahora se dedica solamente a terminar La Florida antes de que muera ${ }^{4}$. La combinación de la modestia afectada con pathos facilita el tono de sacrificio, incapacidad y sufrimiento que, según la retórica, capta la benevolencia del público.

\section{La digresión del fastidium}

Ya señalado en otras digresiones del Inca, el fastidium es sin duda uno de los tópicos favoritos del historiador. La retórica antigua lo recomienda para que el orador capte la benevolencia del público por señalar su deseo de no aburrirles. El Inca se aprovecha de esta recomendación y a veces combina el fastidium con pathos o dubitatio para mayor impacto. En "El gobernador llega a la Florida y halla rastro de Pánfilo de Narváez", escribe de la entrada de los españoles al pueblo del cacique Hirrihigua con quien Narváez había luchado, pero ajusta el fastidium para servir sus propios medios cuando dice: "[. . .] aunque después el indio se había reducido a su amistad, y, durante ella, no se sabe por qué causa, enojado Pánfilo de Narváez, le había hecho ciertos agravios que por ser odiosos no se cuentan" (1965: 274; lib. II, pt. I, cap. I). Juega con el lector en este pasaje de dos maneras: primero, con dubitatio (o vacilación de opinión, Lanham 1969: 38; Cicerón, De Oratore II, 1976: 162, 164), se presenta vulnerable porque no sabe por qué Narváez dejó de mantener su amistad con el indio ("no se sabe por qué causa"). Esta actitud afectada sutilmente provoca el interés del lector en cuanto al comportamiento de Narváez. Luego, después de admitir al lector que sí sabe lo que Narváez hizo contra Hirrihigua ("le había hecho ciertos agravios"), se niega a decírselo bajo un disfraz de decencia ("por ser odiosos no se cuentan"). Así, este uso del fastidium sirve más para "proteger" al lector que para no aburrirle 5 .

En la misma sección, el Inca utiliza el fastidium, en la siguiente digresión, para confesar que tal vez vaya a aburrir al lector pero seguirá adelante con la historia de todos modos:

\footnotetext{
Y para que se vea mejor la rabia que este indio [Hirrihigua] contra los castellanos tenía, será bien decir aquí algunas crueldades y martirios que hizo en cuatro españoles que pudo haber de los de Pánfilo de Narváez, que, aunque nos alarguemos algún tanto, no saldremos del propósito, antes aprovechará mucho para nuestra historia (1965: 274).
}

Obliga al lector a anticipar las anécdotas que vienen; de esta manera, el lector verá que este pequeño desvío realmente ayudará la historia. Otra variación de este tipo de fastidium se encuentra en medio de la descripción de las ocho salas del templo de Cofachiqui en Carolina del Sur. El Inca acaba de guiar al lector por ellas con detalladas descripciones de las grandezas y suntuosidades de las armas ofensivas y defensivas encontradas allí para entierros, cuando inserta en el discurso:

\footnotetext{
[. . . ] y así procuraban engrandecerlos con armas y riquezas, todas las que podían haber, como lo habían visto en aquel templo. Y porque éste fue el más rico y soberbio de todos los que nuestros españoles vieron en la Florida, me pareció escribir tan larga y particularmente las cosas que en él había, y también porque el que me daba la relación me lo mandó así para ser una de las cosas, como él decía, de mayor grandeza y admiración de cuantas había visto en el nuevo mundo [ . . ] (1965: 385-86, lib. III, cap. XVII).
}

Aunque observa que ha escrito mucho de este templo, tiene dos excusas: eran tan impresionantes que no le quedaba más remedio y su fuente reportó que era lo más bello que 
había visto en toda América. En el ejemplo previo de este tipo de fastidium, el Inca primero advierte que va a divagar. Aquí, por contraste, divaga primero para poder advertir después.

Poco después, en el Capítulo IV del mismo libro, el Inca vuelve a emplear el fastidium para presentarse como un modelo de decencia. Explica en "De la magnanimidad del curaca o cacique Mucozo, a quien se encomendó el cautivo”, que Juan Ortiz había vivido con los caciques Hirrihigua y Mucozo por diez años. Mucozo, el bueno, lo había tratado mucho mejor que los "cristianos" de Laino/Bolonia, quienes intercambiaban a sus familiares y a sus amigos inocentes por obtener a sus enemigos y a sus adversarios culpables. Esta práctica de supuestamente grandes príncipes y reyes nunca fue suficientemente proscrita porque según el Inca:

[ . . ] sólo por vengarse de sus enojos, entregaron los que no les habían ofendido por haber los ofensores, dando inocentes por culpados, como lo testifican las historias antiguas y modernas, las cuales dejaremos por no ofender oídos poderosos y lastimar los piadosos (1965: 279).

Aunque pica el interés del lector cuando alude a "las historias antiguas y modernas" de estos agravios, elige no contarlas porque no desea fastidiar a los poderosos y religiosos 6 .

Otro ejemplo similar se nota en el capítulo titulado "De una defensa que un español inventó contra el frío que padecían en Chicaza"; tal invención era una estera suave, larga y blanda de pasto, de un soldado "rústico y grosero" llamado Juan Vego. Pero como veremos, al Inca le interesa más la historia de Vego que su invención:

\footnotetext{
[. . .] al principio de esta jornada, le pasó [a Vego] con Vasco Porcallo de Figueroa un cuento gracioso, aunque para él riguroso, que por ser de burlas y donaires no lo ponemos aquí más de decir que Juan Vego, aunque tosco y grosero, daba en ser gracioso (165: 422; lib. III, cap. XXXIX).
}

Parece que invita al lector a escuchar el cuento "gracioso" de lo que Vego le hizo a Porcallo. Pero al pensarlo, casi casualmente lo retracta, porque sería de mal gusto en este momento, como sustituto, y quizás para jugar con el lector, decide incluir la burla de lo que Porcallo le hizo a Vego:

\begin{abstract}
Vasco Porcallo de Figueroa, que también era amigo de burlas, le hizo una pesada, en cuya satisfacción le dio en la Habana, donde pasó la burla, un caballo alazano que después, en la Florida, por haber salido tan bueno, le ofrecieron muchas veces siete y ocho mil pesos por él para la primera fundición que hubiese [. . .]. Mas Juan Vego nunca quiso venderlo, y acertó en ello, porque no hubo fundición, sino muerte y pérdida de todos ellos, como la historia lo dirá (1965: 422; lib. III, cap. XXXIX).
\end{abstract}

Algunas veces, el Inca parece sincero con el fastidium como vemos al final de "Cómo se empieza el descubrimiento y la entrada de los españoles la tierra adentro":

Los cuatro caballeros anduvieron en dos días las veinte y cinco leguas que hemos dicho sin que en el camino se les ofreciese cosa digna de memoria, donde los dejaremos, por contar lo que entretanto sucedió en el real (1965: 288; lib. II, pt. I, cap. X).

Aquí, el fastidium promueve el deseo del Inca de guiar al lector al siguiente capítulo sin perder tiempo en otro discurso. Si el autor gana tal confianza ahora, el lector estará más dispuesto a aguantar otra digresión larga más tarde; por eso, dejará este tema por hablar de otro.

Pero Garcilaso manosea sutilmente este mismo tipo de fastidium en otro momento, cuando escribe de los "Hechos notables que pasaron en la batalla de Chicaza". Después de hablar del frío de ese invierno, las muertes de unos caballos, las constantes batallas, la valentía del Gobernador Soto y la inquietud perpetua causada por las incursiones nocturnas de los indios, dice: 
En estas refriegas que cada noche tenían, aunque siempre hubo muertos y heridos de ambas partes, no acaecieron cosas particulares notables que poder contar, si no fue una noche que un escuadrón de indios fue a dar donde estaba el capitán Juan de Guzmán y su compañía, el cual salió a ellos a caballo con otros cinco caballeros, y también salieron los infantes (1965: 422; lib. III, cap. XXXVIII).

Ya que había los mismos heridos y muertes de siempre no sucedió nada fuera de lo normal. Por ende, insinúa que por no aburrir a sus lectores dejaría el asunto, si no fuera por la pelea entre los indios y Guzmán que inserta al último momento. Se espera que esta viñeta, a su vez, le conlleve mayor interés al lector porque se agrega al final para "salvar" la importancia del capítulo.

El fastidium favorito del Inca es el que señala la venida de más información, pero solamente en forma limitada. Puede también ser una variación del tópico del brevitas, el cual sugiere que el orador diga solamente una parte de toda la información que puede compartir (Lanham 1969: 20; Cicerón, De Oratore II, 1976: 162). Por utilizarse con una variedad de temas, este tipo de fastidium es el más adaptable en toda La Florida. En el capítulo sobre la llegada de Soto a la provincia de Ocali, el Inca describe la muerte de un perro de un paje de Soto; con miedo, los indios le tiraron cincuenta flechas y murió cuando volvió a su dueño. El Inca entonces explica:

\footnotetext{
[ . . .] al gobernador y a todos los suyos pesó mucho porque era [el perro] pieza rarísima y muy necesaria para la conquista, en la cual, en lo poco que duró, había hecho en los indios enemigos, de noche y de día, suertes de no poca admiración, de las cuales contaremos sola una, que por ella se verá qué tal fue (1965: 299; lib. II, pt. I, cap. XVII).
}

Hubiera habido muchos cuentos más que contar, pero el Inca decide por el lector que solamente uno sirve como ejemplo para captar la importancia de este lebrel; de esta manera, el autor trata de dejar que el lector pida más al retenerle una porción de lo que divulga. Para abrir el Capítulo VIII del Libro Tercero "De un cuento particular acerca de el hambre que los españoles pasaron, y cómo hallaron comida”, el Inca usa la misma estrategia para otra vez limitar lo que dice:

\footnotetext{
Volviendo a la hambre y necesidad que el gobernador y su ejército pasaron aquellos días, me pareció contar un caso particular que pasó entre unos soldados de los más aventajados, que en el real había para que por él se considere y vea lo que se padecería en común, que decir cada cosa en particular sería nunca acabar y hacer nuestra historia muy prolija (1965: 371).
}

Otra vez, una historia sirve para comprenderlas todas. El autor claramente confiesa, en forma afectada, que no quiere hablar sin cesar ni escribir demasiado.

El Inca parece favorecer el fastidium que limita el número de anécdotas de la ferocidad de los indios. En el primero de dos ejemplos, escribe:

\begin{abstract}
Los naturales eran indómitos y temerariamente belicosos, como se ha visto y adelante veremos en algunos casos notables que [. . . entre los españoles e indios acaecieron [. . .] aunque por excusar prolijidad no los contaremos todos. Por los que se dijeren, se verá bien la ferocidad de estos indios de Apalache (1965: 325; lib. II, pt. II, cap. III).
\end{abstract}

Por el mero número de sucesos ya leídos por el lector y que luego leerá, comprende todo lo que necesita de la brutalidad de los indios. No hay necesidad de contarlos todos; la acumulación de cuentos se controla mencionado que hay muchos más, así el lector se rinde y confía en el Inca sin pedir más evidencia, del mismo tema, Garcilaso dice luego:

\footnotetext{
[...] se podrán ver las ferocidades de los indios [. . .] como se verá en el caso siguiente y en otros que se contarán, aunque no todos los que sucedieron que, por huir prolijidad, nos excusaremos de los más (1965: 353; lib. II, pt. II, cap. XXIII).
} 
Atrae al lector primero por decirle que habrá más cuentos de indios, pero califica su oferta después al advertir que no podrá decirle todos por cuestiones de "prolijidad". El mismo tipo de fastidium se combina con pathos para provocar simpatía por los españoles:

\footnotetext{
Con las dificultades y trabajos que hemos dicho, y muchos más que se dejan de decir porque es imposible poderse contar todos los que en semejantes jornadas se padecen[,] pasaron estos treinta valientes y esforzados caballeros el río de Ocali [. . .] (1965: 337; lib. II, pt. II, cap. XIII).
}

El Inca no menciona su "por excusar prolijidad" convencional; en cambio, solamente afirma que "es imposible". Por ende, el lector tiene que adivinar si es por falta de cuentos, cuestión de tiempo o la misma excusa de prolijidad que previenen que siga.

A diferencia de las variaciones anteriores del fastidium, que limitan el discurso prolijo, el Inca tiende a reservar un uso especial en los siguientes casos. Un ejemplo único es cuando Garcilaso termina la descripción de las primeras cinco diferentes salas del templo de Cofachiqui:

\footnotetext{
En la quinta sala había solamente bastones, como los que dijimos que tenían los gigantes de la tercera orden, empero guarnecidos con sus anillos de pelas y aljófar y rapacejos de colores por toda el asta hasta donde empezaba la pala. Y porque el capítulo no salga de la proporción de los demás, diremos en lo siguiente lo que resta (1965: 385; lib. III, cap. XVI).
}

Deja de decir más aquí porque quiere mantener la misma longitud en todos los capítulos. Esta búsqueda de simetría, equilibrio, y armonía es una característica renacentista que la crítica ha visto por excelencia en las obras del Inca (Dowling 1997:100) ${ }^{7}$.

Ya hemos visto el papel importante que desempeña la digresión moralizante y el fastidium, cuando el autor admite que tal vez nos aburra pero sigue adelante de todas maneras. Ahora, los dos se combinan para otro efecto, después de que Soto negocie la paz entre dos caciques indios llamados Casquin y Copaha. El Inca remarca:

\footnotetext{
Escríbanse estas cosas tan por menudo, aunque parece que no son de importancia, porque se vea que la ambición de la honra, más que otra pasión alguna, tiene mucha fuerza en todos los hombres, por bárbaros y ajenos que sean de toda buena enseñanza y doctrina (1965: 439; lib. IV, cap. X).
}

Emplea el tópico su conocimiento de que él sabe que el lector quizás se impaciente algo con el mismo discurso. Admite que sí es verdad, que se repite, pero no tiene más remedio debido a la lección que necesita enseñar de la importancia de la honra para toda la humanidad. Los indios son parte de esa humanidad, porque comparten las mismas pasiones que los cristianos.

Otra combinación de dos tópicos ya estudiados en La Florida se ve en la "Batalla de un indio tula con tres españoles de a pie y uno de a caballo". Para sentar las bases de este cuento sobre un indio, el Inca primero explica que la verdad le obliga a incluir todas las hazañas de ambas naciones, no solamente las de un lado u otro. Después, con disculpa, emplea el fastidium para seguir adelante aunque sabe que aburre a sus lectores: "Y suplicamos no se enfade el que lo oyere porque lo contamos tan particularmente, que el hecho pasó así y en sus particularidades hay qué notar" (445; lib. IV, cap. XIV). Aunque el lector no vea la importancia de sus detalles, el Inca no tiene más remedio que contar las cosas como sucedieron. Luce valiente porque cree que su obligación a ser escritor fidedigno pesa más que el enfado del lector; lo sugiere como un riesgo que él simplemente está dispuesto a correr por la causa de recordar la grandeza de la conquista.

En "Llegan los indios casi a rendir una carabela, y el destino de un español desvanecido", el Inca no se disculpa por divagar sino que pide permiso para hacerlo cuando pregunta: "[y] porque se entienda mejor el mal suceso de los nuestros, se me permita contarlo 
a la larga cómo pasó y qué fue la causa de tanto mal y daño" (497; lib. VI, cap. VI). El pathos del "mal suceso" intenta aumentar simpatía por los españoles mientras contrasta con el ethos del lector quien entenderá "mejor" con esta historia larga.

El fastidium hace un giro imprevisto cuando, hasta el Inca, se impacienta con sí mismo al final de "Lo que sucedió a los tres capitanes exploradores". Primero explica que, debido a que los españoles e indios no se entendieron los unos a los otros, él había puesto aquí la deducción del nombre Perú que los indios de la Florida no tenían en su lenguaje. Pero, como sigue abajo, el plan no salió así porque:

\footnotetext{
[...] por haberse detenido la impresión de este libro más de lo que yo imaginé, lo quité de este lugar y lo pasé al suyo propio, donde se hallará muy a la larga con otros muchos nombres puestos a caso, porque ya en aquella historia, con el favor divino, este año de seiscientos y dos, estamos en el postrer cuarto de ella y esperamos saldrá presto (1965: 511; lib. VI, cap. XV).
}

Emplea el antiguo tópico ciceroniano de "ya se hace tarde" (Curtius 1955: 137) para explicar por qué la deducción no puede estar incluida en La Florida. Entonces, hace un poco de publicidad para su otra historia (Comentarios reales de los incas) que quiere publicar pronto. Luego, en "Prosigue la peregrinación de Gómez Arias y Diego Maldonado", alude a los Comentarios reales otra vez al decir: "[y] de las rebeliones que después en el Perú pasaron diré brevemente lo que oí [. . .]” (1965: 521; lib. VI, cap. XXI). A diferencia de jactarse en el Capítulo XV arriba de los muchos datos que se encontrarán allá, dice aquí con fastidium que solamente hablará "brevemente" de las rebeliones.

\section{La digresión con dubitatio}

Usado mucho menos que el fastidium es el dubitatio (Cicerón, De Oratore 1976: 164-65), otra forma de falsa modestia en la cual el orador se presenta más suplicante si finge que él, como su público, no tiene todas las respuestas. Se combina con sus muchas sentencias, por ejemplo cuando el Inca dice que no sabe por qué Diego Pérez y el corsario francés entraron en treguas (1965: 262) y cuando no entiende por qué Pánfilo de Narváez hizo guerra contra un amigo indio (1965: 274). Otro ejemplo se ve cuando Garcilaso admite que no sabe nombres de provincias en "Cómo se empieza el descubrimiento y la entrada de los españoles la tierra adentro":

\footnotetext{
Los nombres de estas provincias [las de los caciques Urribarracuxi, Mucozo, y Hirrihigua] no se ponen aquí porque no se supo si se llamaban del nombre de los caciques o los caciques del nombre de sus tierras, como adelante veremos que en muchas partes de este gran reino se llama de un mismo nombre el señor y su provincia y el pueblo principal de ella (1965: 287; lib. II, pt I, cap. X).
}

Opta por no incluir de hacerlo incorrectamente. A diferencia de sus quejas de los descuidos de distancias y rumbos de los españoles, no los culpa aquí con los nombres porque nadie puede saberlos.

En otra ocasión, el dubitatio le abre espacio para impresionarnos con sus conjeturas y razonamientos históricos:

\footnotetext{
Y cierto, en este paso y en otros semejantes que la historia dirá, es de considerar cuál fuese la causa que unos mesmos indios, en unos proprios sitios y ocasiones, peleasen unos días con tanta ansia y deseo de matar los castellanos, y otros días no se les diese nada por ello. Yo no puedo dar otra razón sino que para pelear o no pelear debían de guardar algunas abusiones de su gentilidad, como lo hacían algunas naciones en tiempo del grande Julio César, o que por verlos ir de paso y no parar en sus tierras los dejaban (1965: 296; lib. II, pt. I, cap. XV).
} 
Plantea el problema de la inconsistencia de los ataques indios para sentar las bases para su propia respuesta. Al mencionar a César, sugiere que él ha leído las historias del general romano y así compara a los indios con los pueblos enemigos de Roma.

El dubitatio reaparece otra vez en cuanto a la misma falta de ataques indios en "Que cuenta el viaje de los treinta caballeros hasta llegar media legua del pueblo de Hirrihigua". Para introducir el tópico, Garcilaso reemplea la dificultad del desierto:

\footnotetext{
Era gran compasión y lástima ver cuáles salieron los españoles del agua, molidos y hechos pedazos del largo trabajo que pasaron, consumidos del frío que casi todo el día sufrieron, tan quebrantados y cansados que apenas podían tenerse, y con esto es de advertir el poco o ningún regalo que tenían para restaurarse de tanto mal pasado; mas todo lo dieron por bien empleado con haber pasado aquella mala ciénaga que tan temida traían.
}

Después de haber salido de la ciénaga, los soldados no tuvieron que luchar contra la ciénaga y los indios:

\footnotetext{
Dieron gracias a Dios que no hubiesen acudidos enemigos a defenderles el paso, que fue particular misericordia divina, porque si al trabajo que hemos dicho que pasaron se les añadiera haber de pelear y defenderse de solos cincuenta indios, ¿qué fuera de ellos?
}

La pregunta retórica (o ratiocinatio, Lanham 1969: 85; percontatio, Cicerón, De Oratore II, 1979: 162) enciende el pathos por dramatizar el discurso; además, sienta las bases para que el Inca conjeture sobre por qué los indios no se presentaron: "La causa de no haber acudido indios debió ser estar aquella ciénaga lejos de poblado y ser ya invierno, que entonces, porque andan desnudos, acostumbran salir poco de sus casas" (1965: 340; lib. II, pt. II, cap. $\mathrm{XV}$ ). Sin saber la razón con datos específicos, él adivina que la distancia y el frío colaboraron para salvar a los españoles de una muerte segura.

Luego, en "Pasa el ejército el río de Cofachiqui y alójase en el pueblo y envían a Juan de Añasco por una viuda”, el dubitatio permite que el Inca elogie a la señora india mientras se queja de la invasión española. Cuando los españoles conocieron a la Señora quedaron tan enamorados de su discreción y hermosura que:

\section{[...] después no fueron para saber cómo se llamaba, sino que se contentaron con llamarla señora, y tuvieron razón, porque lo era en toda cosa. Y como ellos no supieron el nombre, no pude yo ponerlo aquí, que muchos descuidos de estos y otros semejantes hubo en este descubrimiento (1965: 376; lib. III, cap. XI).}

El Inca comprende cómo su belleza y gentileza los captivaron bastante para que se olvidaran de preguntar su nombre; sin embargo, le irrita que este tipo de omisión perjudique su historia varias veces.

Empero, a veces, la ausencia de datos exactos no se debe a los españoles, sino a la memoria decadente del Inca, como vemos en "Hacen los españoles una puente y pasan el río de Ocali y llegan [a] Ochile". Aquí explica que los indios habían dividido su territorio entre tres hermanos; el Inca recuerda que Vitachuco, el mayor de ellos, gobernaba cinco de las diez partes de la provincia. Pero, del otro hermano, dice, “[y] el segundo, cuyo nombre por haberse ido de la memoria no se pone aquí, poseía de las otras cinco, las tres (301; lib. II, pt. II, cap. XIX). Finalmente, casi al final de la historia el dubitatio ayuda a que Garcilaso haga una revelación sorprendente sobre sus propios escritos cuando dice:

\footnotetext{
[...] muchas veces me pesó hallarlas [cosas tan buenas de los indios] en el discurso de la historia tan magníficas y excelentes, porque no se sospechase que eran ficciones mías y no cosecha de la tierra, de lo cual me es testigo Dios Nuestro Señor, que no solamente no he añadido cosa alguna a la relación que
} 
se me dio, antes confieso con vergüenza y confusión mía no haber llegado a significar las hazañas como me las recitaron que pasaron [. . .] (520; lib. VI, cap. XXI).

Se queja afectadamente de que no pueda escribir de la misma manera como le dijeron la informacón. Su confesión con "confusión” sugiere que no sabe por qué no ha podido hacerlo.

\section{La digresión del carnaval}

Miró Quesada-Sosa ha vista en La Florida el gusto por la narración "al estilo de las novelas italianas" que suele incluir escenas de fiestas "enaltecidas por la 'lindeza de la gala", (1989: 161). Por incorporar el carnaval en La Florida, el Inca se incluye en el largo continuum de este tópico en la literatura hispanoamericana. La tradición se inicia por Colón, quien retrata el Caribe como un lugar feliz lejos de las preocupaciones de la vida con sus descripciones de la felicidad de los indígenas, la eterna primavera y la abundancia de flora y fauna de la naturaleza (Diario 1992: 121, 127, 130). En 1608, el cubano, Silvestre de Balboa, recoge el tópico de la hospitalidad y la fruta caribeñas en su poema, El espejo de paciencia, donde las ninfas y vecinos de Bayamo alegremente ofrecen al pastor liberado las plantas y animales de la isla:

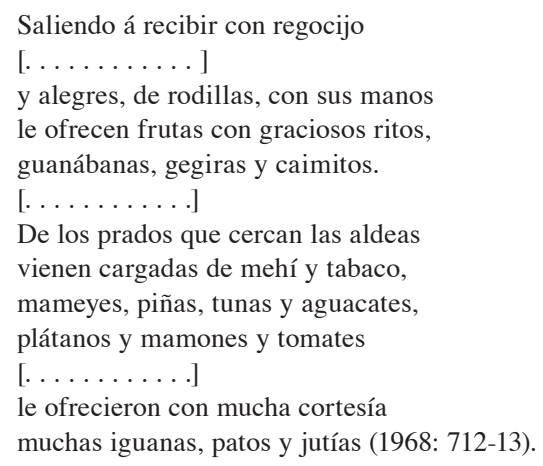

Vemos el mismo tipo de celebración luego en Los infortunios de Alonso Ramírez. (1690), donde Carlos Sigüenza y Góngora describe el encuentro entre el náufrago Ramírez y dos otros "católicos" en las playas de Yucatán. Al enterarse de que todos son españoles, los hombres ofrecen "repetidas gracias" a Dios, disparan para que vengan los otros compañeros escondidos y "con su venida, que fue inmediata y acelerada, fue común entre todos el regocijo" (1990: 139). Hasta el narrador del Periquillo Sarniento (1816) recoge dicha alegría cuando recuerda que en la isla de Saucheofú el rey Limahotón "[...] mandó a sus criados que me llevaran en hombros. Al instante se suscitó un leve murmullo entre los espectadores que remató un sinnúmero de vivas y exclamaciones" (Lizardi 1968: 329). Esta recepción en hombros nos lleva a Alejo Carpentier, quien emplea la imagen de la conga carnavalesca en su Concierto barroco (1974): "[...] formaron todos una fila, agarrados por la cintura, moviendo las caderas, en la más descoyuntada farándula que pudiera imaginarse [...]. Así en fila danzante y culebreante, uno detrás de otro, dieron varias vueltas a la sala [...]" (1989: 46). Hasta hoy, la publicidad de los cruceros y lugares de veraneo siguen promoviendo el Caribe como un escape divertido lleno de romance y alegría.

No es sorprendente entonces que el Inca use el mismo tópico tanto para empezar como terminar La Florida. Aunque en ambos momentos la expedición de Soto está en o cerca del Caribe, los españoles tienen muy diferentes motivos para celebrar como primero vemos en "De las fiestas que al gobernador hicieron en Santiago de Cuba": 
Viéndose la ciudad con dos personajes tan principales para el gobierno de ambos estados, eclesiástico y seglar, no cesó por muchos días de festejarlos, unas veces con danzas, saraos y máscaras que hacían de noche; otros con juegos de cañas y toros, que corrían y alanceaban; otros días hacían regocijo a la brida, corriendo sortija (1965: 265; lib. I, cap. XI).

Todos los elementos que se imaginan para el carnaval tropical están: danzas y máscaras para el desfile, saraos con bebidas y comida, y una cantidad de juegos y competencias con animales y equipo. La fiesta es de anticipación, esperanza y verdadero júbilo.

El tópico caribeño reaparece en el Libro Sexto con algunos elementos nuevos. Aquí, al ver la prueba de que están finalmente en México después de cuatro años perdidos, los tres capitanes exploradores "hicieron gran fiesta teniendo las señales por cierta y dichosas conforme al deseo de ellos" (1965: 510; cap. XV). Para compartir las buenas noticias con los otros "[. . .] anduvieron hasta que llegaron a la costa donde los demás compañeros estaban haciendo gran fiesta y regocijo con los pedazos de plato y escudilla que los otros exploradoes habían traído" (1965:511). Cuando un indio pronunció "tijeras" como "tiselas" fue la prueba verbal final de que habían llegado, como el Inca explica:

Con esta palabra, aunque mal pronunciada, acabaron de certificarse los nuestros que estaban en tierra de México, y con el regocijo de entenderlo así a porfía abrazaban y daban paz en el rostro a Gonzalo Silvestre y a los de su cuadrilla, y en brazos los levantaban en alto hasta ponerlos sobre sus hombros y traerlos paseando, diciéndoles grandezas y loores sin tiento ni cuenta [...] (1965:511).

Los soldados formaron una especie de conga a la de Carpentier para llevar al otro Silvestre sobre sus hombros a lo de Lizardi. Estos hombres en México eran unos de los pocos sobrevivientes de la multitud que celebró cuatro años antes en Cuba. Así, la famosa imagen del Caribe feliz se perpetuó aunque la realidad decía lo contrario.

\section{Notas}

1. Granada dice que esta técnica ocurre "quando muchas palabras de una misma significación se juntan para instar, aumentar y tal qual vez tambien para hablar con mayor claridad" (340). Lanham la llama "interpretatione" o una repetición o amplificación en otras palabras (60). En el mismo capítulo, el Inca sigue jugando con otras interpretaciones de la misma raíz: "[. . .] quiso el gobernador ser el descubridor del camino, porque en los trances y pasos dificultosos, si él mismo no les descubría, no se satisfacía de otro. Con esta determinación volvió a pasar la ciénega destotra parte y, eligiendo cien caballos y cien infantes que fuesen con él, dejó el resto del ejército donde se estaba con el maese de campo y caminó tres días la ciénega arriba [. . .]" (291, énfasis es mío). Todavía otra se ve en, "[e]mpero mejor fuera remitir el castigo a los indios, que ellos curaran su locura, como se la curaron, y no enviar a perder otros muchos que se perdieron por un perdido" (498, énfasis es mío).

2. El Inca se queja de lo mismo otra vez en el Capítulo III del Libro Cuarto: "Decimos que el gobernador salió de Guancane hacia el Poniente en demanda del Río Grande, y es así que, aunque en este paso, y en otros de esta nuestra historia, hemos dicho la derrota que el ejército tomaba cuando salía de unas provincias para ir a otras, no ha sido con la demostración de los grados de cada provincia, ni con señalar derechamente el rumbo que los nuestros tomaban, porque, como ya en otra parte [291] he dicho, aunque o procuré saber, no me fue posible, porque quien me daba la relación, por no ser cosmógrafo ni marinero, no lo sabía, y el ejército no llevaba instrumentos para tomar la altura, ni había quien lo procurase ni mirase en ello, porque, con el disgusto que todos traían de no hallar oro ni plata, nada les sabía bien. Por lo cual se me perdonará esta falta con otras muchas que esta mi obra lleva, que yo holgara que no hubiera de qué pedir perdón" (455). Lo menciona por tercera vez en el Capítulo IX del Libro Quinto (Segunda Parte): "Cuando Dios fuere servido que se gane aquella tierra, verán por este río lo que los nuestros se 
alejaron de la mar, que por ahora yo no puedo verificar más esta relación de cómo la escribo. Y aún ha sido mucho haber sacado en limpio esto poco, al cabo de tantos años que ha que pasó y por gente que su fin no era andar demarcando la tierra, aunque la andaban descubriendo, sino buscar oro y plata. Por lo cual se me podrá admitir en este lugar el descargo que en otras he dado [e.g. 291, 455] de las faltas que esta historia lleva en lo que toca a la cosmografía, que yo quisiera haberla escrito muy cumplidamente para dar mayor y mejor noticia de aquella tierra [. . .]" (502).

3. Es un tipo de falsa modestia llamada excusatio propter infirmitatem en que el orador alude a su propia debilidad (Curtius 1955: 127).

4. Su discurso de mala salud aquí puede ser un ejemplo del antiguo tópico de concluir debido al cansancio y la fatiga (Curtius 1955: 137).

5. También puede ser una manifestación del tópico de "lo indecible" ( pauca e multis) por el cual el autor no dice sino muy poco de lo mucho que quisiera expresar (Curtius 1955: 232).

6. Los oídos poderosos" y "los piadosos" pueden ser ejemplos de los siguientes tropos retóricos usados en lugar de decir "la Santa Inquisición": 1) la perífrasis (circuitio), frecuentemente usada por los culteranos y conceptistas como un "rodeo expresivo para aludir a algo evitando su nombre" (Lázaro-Carreter 1968: 1). El uso de este tropo contrasta con la opinión de muchos estudiosos de que Garcilaso era más alineado con la poética del Renacimiento que con la del Barroco (Dowling 1997: 100); 2) la antonomasia, o el uso "de un nombre por otros de una cualidad que le corresponde de manera inconfundible" (Lázaro-Carreter 1968: 12); o la metonimia que responde a la fórmula de "una parte en lugar de otra parte" (LázaroCarreter 1968: 6). Aquí, los "oídos" representan todo el cuerpo aunque son solamente la parte auditiva. Además, la repetición de la "p," "d," y "osos" en "poderosos" con "piadosos" forman una aliteración mientras la proximidad de estas palabras parecidas es una paronomasia (Lázaro-Carreter 1968: 1,7).

7. En "Sale Pedro Calderón con su gente, y el suceso de su camino hasta llegar a la ciénega grande," el mismo tópico de orden y equilibrio se observa cuando el Inca remarca, "[d]e otros tiros dignos de fama que hubo en este descubrimiento haremos mención adelante en los lugares donde acaecieron que cierto son para admirar" (347; lib. II, pt. II, cap. XVIII). Sin embargo, parece vacilar con su propia regla estricta cuando contempla en otro momento, "[o]lvidándosenos ha de haber dicho atrás, en su lugar, un ejemplar castigo que el capitán Patofa hizo en un indio de los suyos. Por ser tan extraño será razón que no quede en olvido y caerá bien dondequiera que se ponga" (370; lib. III, cap. VII). Afirma que "se le olvidó" cuando lo hubiera dicho "en su lugar" pero al pensarlo ahora no importa donde vaya.

\section{Bibliografía}

Aristóteles. 1985. Poetics. Gerald F. Else (ed. y trad.). Ann Arbor: U de Michigan P.

1985. Rhetoric. The Complete Works of Aristotle. Vol. II. Jonathan Barnes (ed.). Princeton: Princeton UP, 2152-2269. 2 vols.

Balboa, Silvestre de. 1968.1608. "El espejo de paciencia." "El 'Espejo de paciencia,' primer poema épico-histórico de las letras cubanas". Ángel Aparicio Laureano (ed.). Cuadernos Hispanoamericanos. 228: 707-30. 
Carpentier, Alejo. 1989. Concierto barroco. $21^{\mathrm{a}}$ ed. México, D.F.: Siglo Veintiuno.

Cicerón. 1976. De Oratore. T.E. Page y H. Rackman (eds.). E.W. Sutton y H. Rackman (trads.). Cambridge: Harvard UP. 2 vols.

Colón, Cristóbal. 1992. Textos y documentos completos. $2^{\mathrm{a}}$ ed. Gual Gil (ed.). Madrid: Alianza.

Cruz-Hernández, Miguel. 1977. El pensamiento de Ramón Lull. Madrid: Castalia.

Curtius, Ernest. 1955. Literatura europea y Edad Media Latina. Margit Frenk Alatorre y Antonio Alatorre (trad.). Vol. 1. México, D.F.: Fondo de Cultura Económica.

Dowling, Lee. 1997. “La Florida del Inca: Garcilaso’s Literary Sources”. En: Patricia Galloway (ed.), 98-154.

Galloway, Patricia (ed.). 1997. The Hernando de Soto Expedition: History, Historiography, and "Discovery" in the Southeast. Lincoln: U of Nebraska P.

Góngora, Carlos de Sigüenza y. 1990. Los infortunios de Alonso Ramírez. Estelle Irizarry (ed.). San Juan: Comisión Puertorriqueña para la Celebración del Quinto Centenario del Descubrimiento de América y Puerto Rico.

Granada, Luis de. 1778. Rhetorica eclesiastica. Barcelona: Juan Jolis, Repub. de Ecclesiasticae Rhetoricae: sive de ratione concionandi. 1576.

Lanham, Richard. 1969. A Handlist of Rhetorical Terms. Berkeley: U de California P.

Lavalle, Bernard. 1982. "El Inca Garcilaso de la Vega”. Madrigal, 135-43.

Lázaro-Carreter, Fernando. 1968. Diccionario de términos filológicos. Madrid: Gredos.

Lizardi, José Joaquín Fernández de. 1968. El Periquillo Sarniento. $9^{a}$ ed. Jefferson Rea Spell (ed.). México, D.F.: Porrúa.

Madrigal, Luis Iñigo (ed.). 1982. Historia de la literatura hispanoamericana. Vol. 1. Madrid: Cátedra.

Mignolo, Walter. 1982. "Cartas, crónicas y relaciones del descubrimiento y la Conquista". Madrigal, 57-119.

Miró-Quesada Sosa, Aurelio. 1989. "Creación y elaboración de La Florida del Inca". Cuadernos Americanos. 3 (18): 152-71. 
Paravicino, Hortensio. 1994. Sermones cortesanos. Francis Cerdán (ed.). Madrid: Castalia.

Rabasa, José. 2000. Writing Violence on the Northern Frontier. Durham: Duke UP.

Sáenz de Santa María, P. Carmelo (ed.). 1965. Obras completas del Inca Garcilaso de la Vega. Vol. 1. Biblioteca de Autores Españoles (BAE). Vol. 152. Madrid: Atlas.

Smith, Hilary Dancey. 1978. Preaching in the Spanish Golden Age. Oxford: Oxford UP.

Vega, Inca Garcilaso de la. 1965. La Florida. 1605. En: Sáenz de Santa María, 241-524. 